\title{
Scale/Analytical Analyses of Freezing and Convective Melting with Internal Heat Generation
}

\section{HT2013}

The INL is a

U.S. Department of Energy

National Laboratory

operated by

Battelle Energy Alliance

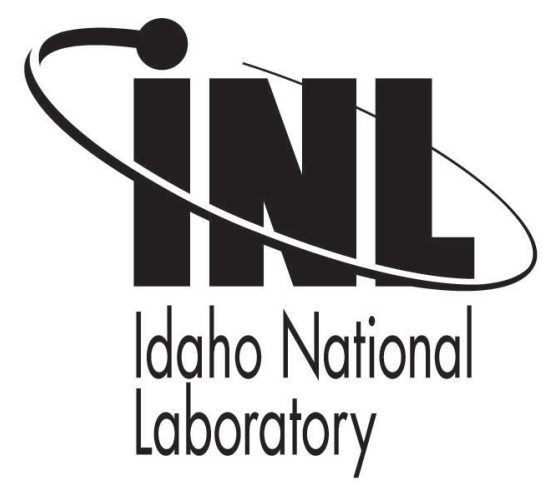

\section{Ali Siahpush \\ John Crepeau \\ Piyush Sabharwall}

\author{
July 2013
}

This is a preprint of a paper intended for publication in a journal or proceedings. Since changes may be made before publication, this preprint should not be cited or reproduced without permission of the author. This document was prepared as an account of work sponsored by an agency of the United States Government. Neither the United States Government nor any agency thereof, or any of their employees, makes any warranty, expressed or implied, or assumes any legal liability or responsibility for any third party's use, or the results of such use, of any information, apparatus, product or process disclosed in this report, or represents that its use by such third party would not infringe privately owned rights. The views expressed in this paper are not necessarily those of the United States Government or the sponsoring agency. 


\section{SCALE/ANALYTICAL ANALYSES OF FREEZING AND CONVECTIVE MELTING WITH INTERNAL HEAT GENERATION}

\author{
Ali Siahpush \\ Idaho National Laboratory \\ Idaho Falls, Idaho, USA
}

\author{
John Crepeau \\ University of Idaho \\ Moscow, Idaho, USA
}

\author{
Piyush Sabharwall \\ Idaho National Laboratory \\ Idaho Falls, Idaho, USA
}

\begin{abstract}
Using a scale/analytical analysis approach, we model phase change (melting) for pure materials which generate constant internal heat generation for small Stefan numbers (approximately one). The analysis considers conduction in the solid phase and natural convection, driven by internal heat generation, in the liquid regime. The model is applied for a constant surface temperature boundary condition where the melting temperature is greater than the surface temperature in a cylindrical geometry. The analysis also consider constant heat flux (in a cylindrical geometry).We show the time scales in which conduction and convection heat transfer dominate.
\end{abstract}

\section{NOMENCLATURE}

$\mathrm{a}, \mathrm{b}, \mathrm{c}-\mathrm{constants}$

$\mathrm{c}_{1}, \mathrm{c}_{2}-$ constants

$\mathrm{c}_{\mathrm{p}}$ - specific heat $(\mathrm{kJ} / \mathrm{kg} \mathrm{K})$

$\mathrm{g}-$ gravitational constant $\left(\mathrm{m} / \mathrm{s}^{2}\right)$

$\Delta \mathrm{h}_{\mathrm{f}}-$ latent heat $(\mathrm{kJ} / \mathrm{kg})$

$\mathrm{k}-$ thermal conductivity $(\mathrm{W} / \mathrm{m} \mathrm{K})$

$\dot{q}$ - internal heat generation $\left(\mathrm{W} / \mathrm{m}^{3}\right)$

$\mathrm{q}^{\prime \prime}$ - surface heat flux $\left(\mathrm{W} / \mathrm{m}^{2}\right)$

$\mathrm{r}$ - radial distance $(\mathrm{m})$

$\mathrm{s}$ - distance from CL to phase front (m)

$\mathrm{St}-$ Stefan number $\left(\mathrm{c}_{\mathrm{p}} \Delta \mathrm{T} / \Delta \mathrm{h}_{\mathrm{f}}\right)$

$\mathrm{t}$ - time $(\mathrm{s})$

$\mathrm{T}$ - temperature $(\mathrm{K})$

$\mathrm{T}_{\mathrm{m}}$ - melting temperature $(\mathrm{K})$

$\mathrm{u}, \mathrm{w}$ - velocity components $(\mathrm{m} / \mathrm{s})$

$\mathrm{z}$ - spatial components $(\mathrm{m})$

Greek

$\alpha$ - thermal diffusivity $\left(\mathrm{m}^{2} / \mathrm{s}\right)$

$\beta$ - coefficient of thermal expansion $(1 / \mathrm{K})$

$\delta_{z}-$ convection thermal boundary layer thickness $(\mathrm{m})$

$\mu$ - dynamic viscosity $(\mathrm{kg} \mathrm{m} / \mathrm{s})$

$v$ - kinematic viscosity $\left(\mathrm{m}^{2} / \mathrm{s}\right)$

\author{
$\rho$ - density $\left(\mathrm{kg} / \mathrm{m}^{3}\right)$ \\ $\theta$ - nondimensional time, $\left(\dot{q} / \rho \Delta \mathrm{h}_{\mathrm{f}}\right)$

$$
\begin{aligned}
& \text { Subscripts } \\
& \text { CL-centerline } \\
& \mathrm{f}-\text { fusion } \\
& 1 \text { - liquid } \\
& \mathrm{s}-\text { solid } \\
& 0 \text { - initial value } \\
& \infty \text { - freestream }
\end{aligned}
$$

\section{INTRODUCTION}

Many physical systems, including geophysics, cryosurgery and materials processing among others involve solid-liquid phase change driven by internal heat generation. One of the prime examples is in nuclear systems, where fuel rods may melt during accident scenarios. The nonhomogeneous heat generation term in the energy equation makes an exact solution difficult to find. Complicating the solution is convection in the liquid phase of the material. Viskanta [1] has reviewed the literature regarding natural convection in melting and solidification processes. Early analytical studies on free convection driven by internal heat generation with no phase change in a vertical cylinder were performed by Martin [2]. He used the integral method to find temperature and velocity profiles within the cylinder. Vajravelu [3] studied natural convection driven by internal heat generation in a fluid on the surface of a heated semi-infinite vertical plate. He found that the heat sources considerably increased the temperature and velocity fields. Daniels and Jones [4] used the method of matched asymptotic expansions to find steady two-dimensional motion generated in a shallow cavity by uniformly distributed internal heat sources. Their solutions showed how the Rayleigh number influences the shape and speeds of the convection cells formed in the shallow rectangular cavity. Tasaka et al. [5] investigated experimentally natural convection induced by internal heat generation, showing that the convection cells dilate with increasing Rayleigh number. They used 
thermochromic liquid crystals to visualize the motion of the convection cells. The temperature profiles show that the high temperature areas within the cell occur at the apexes. An analytical study for natural convection in a cavity of different aspect ratios with a uniform volumetric heat generation was performed by Joshi et al. [6]. They found that the horizontal component of the velocity is smaller than the vertical component near the center and walls of the cavity. They compared their results to computational results showing good agreement. Approximate solutions of phase change with natural convection were studied by Tien and Yen [7]. They found good comparisons of their analytical solutions to numerical ones for water-ice systems.

The scale analysis technique introduced by Bejan [8] is used in this paper to analyze phase change and natural convection with internal heat generation. The scale analysis method evaluates order-of-magnitude estimates for the behavior for physical systems. This method has also been used and described by Astarita [9] to gain significant physical insight to various problems. Zhang and Bejan [10] used scale analysis to study time-dependent natural convection melting with conduction in the solid. They found that in the conduction dominated regime, the Nusselt number increases as the solid subcooling parameter increases. Scale analysis was also used to study turbulent heat transfer driven by buoyancy in a porous layer with homogeneous heat sources by Kim and Kim [11]. They found a critical Rayleigh number for the onset of natural convection.

In this paper, we model natural convection driven by internal heat generation. This is an extension to numerical work published previously [12].

The cylindrical geometry is given in Figure 1. Because of the internal heat generation of the material, the center portion of the cylinder melts first, and we assumed that the internal heat generation is the same in both the liquid and solid phases. We also assume that the material is pure, so that the material has a single melting temperature, $T_{m}$, and there is no mushy zone. We have performed scale analysis for both constant temperature and constant surface heat flux boundary conditions along the surface of the cylinder since both boundary conditions are experienced based on the nuclear reactor.

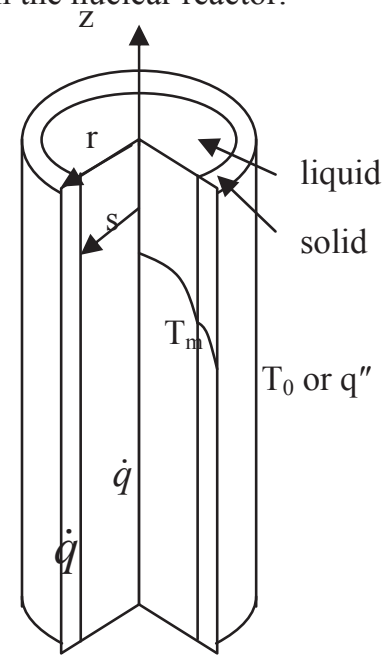

Figure 1. Schematic diagram of phase change in a cylinder with volumetric heat generation

\section{MELTING WITH CONSTANT HEAT FLUX BOUNDARY CONDITIONS}

We begin the scale analysis of melting in a cylindrical system with internal heat generation and constant heat flux boundary conditions using the conservation of mass, momentum and energy equations [13],

$$
\begin{gathered}
\frac{\partial u}{\partial r}+\frac{\partial w}{\partial z}=0 \\
u \frac{\partial w}{\partial r}+w \frac{\partial w}{\partial z}=-g \beta \Delta T_{s}+v\left(\frac{\partial^{2} w}{\partial r^{2}}+\frac{1}{r} \frac{\partial w}{\partial r}+\frac{\partial^{2} w}{\partial z^{2}}\right) \\
u \frac{\partial T}{\partial r}+w \frac{\partial T}{\partial z}=\frac{\dot{q}}{\rho c_{p}}+\alpha\left(\frac{\partial^{2} T}{\partial r^{2}}+\frac{1}{r} \frac{\partial T}{\partial r}+\frac{\partial^{2} T}{\partial z^{2}}\right)
\end{gathered}
$$

Note that in this analysis, the continuity and momentum equations are not used and the analysis solely relies on the conduction equation and the assumed temperature profile in the liquid region. Also the one dimensional analysis is performed and origin of the $\mathrm{z}$ axis is not shown in Figure 1. We apply the constant heat flux condition at the surface of the cylinder, where $r=r_{0}$,

$$
q^{\prime \prime}=-\left.k_{s} \frac{d T_{s}}{d r}\right|_{r=r_{0}}
$$

At the interface between the solid and liquid regimes, an energy balance shows [14],

$$
\left.k_{l} \frac{d T_{l}}{d r}\right|_{r=s}+\rho_{s} \Delta h_{f} \frac{d s}{d t}=\left.k_{s} \frac{d T_{s}}{d r}\right|_{r=s}
$$

Equation (5) can be used to solve for the time rate of change of the location of the solid-liquid phase front. In order to do so, the temperature gradients in both the liquid and solid phases must be determined. This is done by starting with the heat diffusion equation in cylindrical coordinates, applied in the solid phase, assuming a constant thermal conductivity and conduction in the radial direction gives,

$$
\frac{1}{r} k_{s} \frac{d}{d r}\left(r \frac{d T}{d r}\right)+\dot{q}=0
$$

After integrating Eq. (6) twice and solving for the temperature, we find,

$$
T(r)=-\frac{\dot{q}}{2 k_{s}} \frac{r^{2}}{2}+c_{1} \ln r+c_{2}
$$

with boundary conditions given by Eq. (4) and, $T(r=s)=T_{\mathrm{m}}$, where $T_{\mathrm{m}}$ is the melting temperature of the solid.

After applying the two boundary conditions, we can solve for the two constants of integration to get, 


$$
\begin{aligned}
& c_{1}=\frac{\dot{q}}{2 k_{s}} r_{o}^{2}-\frac{q^{\prime \prime}}{k_{s}} r_{0} \\
& c_{2}=\frac{\dot{q}}{4 k_{s}} s^{2}-c_{1} \ln s+T_{m}
\end{aligned}
$$

Inserting the constants given in Eq. (8) into Eq. (7) yields the temperature profile in the solid phase,

$$
\begin{gathered}
T-T_{m}=-\frac{\dot{q}}{4 k_{s}}\left(r^{2}-s^{2}\right)+ \\
\left(\frac{\dot{q}}{2 k_{s}} r_{0}^{2}-\frac{q^{\prime \prime}}{k_{s}} r_{0}\right) \ln \left(\frac{r}{s}\right)
\end{gathered}
$$

And the temperature gradient in the solid phase becomes,

$$
\frac{d T_{s}}{d r}=-\frac{\dot{q} s}{2 k_{s}}\left(\frac{r_{0}^{2}}{s^{2}}-1\right)-\frac{q^{\prime \prime}}{k_{s}} \frac{r_{0}}{s}
$$

Since the temperature profile in the materials with internal heat generation is expected to be parabolic, we can assume a temperature profile in the liquid region of the form,

$$
T_{l}=a+b r+c r^{2}
$$

For the boundary conditions in the liquid region, $T(r=0)=T_{\mathrm{CL}}$, $T(r=s)=T_{\mathrm{m}}$ and $d T / d r=0$ at $r=0$. Applying these conditions into Eq. (11) yields the temperature profile,

$$
T_{l}(r)=T_{C L}-\frac{T_{C L}-T_{m}}{s^{2}} r^{2}
$$

and the temperature gradient,

$$
\frac{d T_{l}}{d r}=-\frac{2\left(T_{C L}-T_{m}\right)}{s^{2}} r
$$

Note that the temperature at the centerline, $T_{C L}$ is assumed to be known. Substituting Eqs. (10) and (13) into the interface equation, Eq. (5), yields the relation,

$$
-2 k_{l}\left(T_{C L}-T_{m}\right)+\rho_{s} \Delta h_{f} s \frac{d s}{d t}=-\frac{\dot{q}}{2} s^{2}+\frac{1}{4} \dot{q} r_{0}^{2}-q^{\prime \prime} r_{0}
$$

We can now look at the relative magnitude of each term through a scale analysis. The scales can be shown to be,

$$
k_{l} \Delta T_{l}, \rho_{s} \Delta h_{f} \frac{s^{2}}{t} \sim \dot{q} s^{2}, \dot{q} r_{0}^{2}, q^{\prime \prime} r_{0}
$$

When the material begins to melt, $\dot{q} r_{0}^{2}>\dot{q} s^{2}$ until the melt front reaches the radius of the cylinder. Eliminating the $\dot{q} s^{2}$ term and multiplying both sides of the equation by $c_{p} / \Delta h_{f}$, gives,

$$
k S t_{l}, \rho c_{p} \frac{s^{2}}{t} \sim \frac{c_{p}}{\Delta h_{f}}\left(\dot{q} r_{0}^{2}, q^{\prime \prime} r_{0}\right)
$$

where $S t_{l}$ is the Stefan number for the liquid, $S t_{l}=c_{p} \Delta T_{l} / \Delta h_{f}$. If $S t_{l}$ is small then $k_{l} S t_{l} \rightarrow 0$. This then gives,

$$
\rho_{s} \Delta h_{f} \frac{s^{2}}{t} \sim \dot{q} r_{0}^{2}, q^{\prime \prime} r_{0}
$$

We can investigate the scaling here for two cases. If $\dot{q} r_{0}^{2} \gg q^{\prime \prime} r_{0}$, then,

$$
\rho_{s} \Delta h_{f} \frac{s^{2}}{t} \sim \dot{q} r_{0}^{2}
$$

so that the melting front scales as,

$$
s \sim\left(\frac{\dot{q} r_{0}^{2}}{\rho_{s} \Delta h_{f}} t\right)^{1 / 2}
$$

The scale described in Eq. (19) ends when $s$ reaches $r_{0}$.

In the second case, when, $q^{\prime \prime} r_{0} \gg \dot{q} r_{0}^{2}$, then $s$ scales as,

$$
s \sim\left(\frac{q^{\prime \prime} r_{0}}{\rho_{s} \Delta h_{f}} t\right)^{1 / 2}
$$

which is independent of $\dot{q}$.

\section{FREEZING WITH CONSTANT SURFACE HEAT FLUX BOUNDARY CONDITIONS}

We now consider the problem of freezing in the cylindrical geometry where the material generates internal heat, and there is no convection in the liquid phase. We again consider the boundary condition as given in Eq. (4). Since there is a constant surface heat flux condition, the temperature at the surface, in general varies. We assume initially that the material is completely liquid and that freezing occurs from the outer portion of the cylinder and moves to the centerline. Previously, Crepeau and Siahpush [15] showed,

$$
s \frac{d s}{d t}=\frac{r_{0}}{\rho_{s} \Delta h_{f}}\left(\frac{\dot{q} r_{0}}{2}-q^{\prime \prime}\right)
$$

This equation may be solved analytically and the result is presented as,

$$
s=\sqrt{\frac{2 r_{0}}{\rho_{s} \Delta h_{f}}\left(\frac{\dot{q} r_{0}}{2}-q^{\prime \prime}\right)}
$$

It is clear from Eq. (21) that when the internal heat generation multiplied by $r_{0} / 2$ is equal to the heat flux out of the system, 
that the energy balances and the system is in steady-state. Equation (21) then scales like,

$$
\frac{s^{2}}{t} \sim \frac{\dot{q} r_{0}^{2}}{\rho_{s} \Delta h_{f}}, \frac{q^{\prime \prime} r_{0}}{\rho_{s} \Delta h_{f}}
$$

If $\left|\dot{q} r_{0}\right|>\left|q^{\prime \prime}\right|$, then no solidification occurs since the amount of heat generated by the materials exceeds that which is transferred out at the surface. In this case, $s=r_{0}$ and there is no melting.

When $\left|\dot{q} r_{0}\right|<\left|q^{\prime \prime}\right|$, solidification begins, and here, $s$ scales like,

$$
s \sim\left(\frac{q^{\prime \prime} r_{0}}{\rho_{s} \Delta h_{f}}\right)^{1 / 2} t^{1 / 2}
$$

Equation (22) is compared with Eq. (24) and the result is presented in Figure 2. In this evaluation, it is assumed that $r_{0}=0.2 \mathrm{~m}$, and freezing of $\mathrm{UO}_{2}$ considered. El-Genk and Cronenberg [16] gave the properties of $\mathrm{UO}_{2}$ which are used in this scale analysis and are listed in Table 1 . Note that at $t=0$, $s=r_{0}$ and freezing starts at the outer wall of the cylinder and proceeds inward.

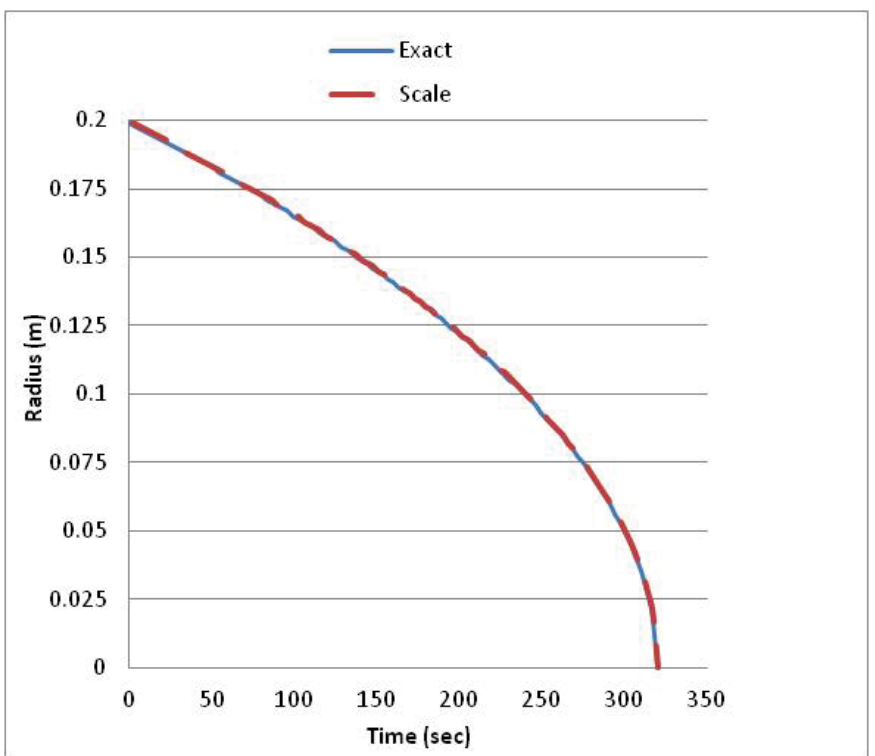

Figure 2. Freezing with constant heat flux.

\section{FREEZING WITH CONSTANT TEMPERATURE BOUNDARY CONDITIONS}

We now consider the case of freezing with the case of constant temperature boundary conditions in a cylindrical geometry. In this case, $T_{m}>T_{0}$. The interface equation is given in Eq. (5) and the time-dependent governing equation is,

$$
\frac{1}{r} \frac{d}{d r}\left(k r \frac{d T}{d r}\right)+\dot{q}=\rho c_{p} \frac{\partial T}{\partial t}
$$

Table $1 . \mathrm{UO}_{2}$ properties

\begin{tabular}{|l|l|}
\hline Melt temperature & $\mathrm{T}_{\mathrm{m}}=2877^{\circ} \mathrm{C}$ \\
\hline Heat of fusion & $\Delta \mathrm{h}_{\mathrm{f}}=65.543 \mathrm{cal} / \mathrm{gm}$ \\
\hline Specific heat of solid & $\mathrm{c}_{\mathrm{ps}}=0.579 \mathrm{cal} / \mathrm{gm}^{\circ} \mathrm{C}$ \\
\hline Specific heat of liquid & $\mathrm{c}_{\mathrm{pl}}=0.1194 \mathrm{cal} / \mathrm{gm}^{\circ} \mathrm{C}$ \\
\hline $\begin{array}{l}\text { Thermal conductivity } \\
\text { of liquid }\end{array}$ & $\mathrm{k}_{\mathrm{l}}=5.97 \times 10^{-3} \mathrm{cal} / \mathrm{cm}^{\circ} \mathrm{C} \mathrm{sec}$ \\
\hline $\begin{array}{l}\text { Thermal conductivity } \\
\text { of solid }\end{array}$ & $\mathrm{k}_{\mathrm{s}}=5.97 \times 10^{-3} \mathrm{cal} / \mathrm{cm}^{\circ} \mathrm{C} \mathrm{sec}$ \\
\hline Density of solid & $\rho_{\mathrm{s}}=10530 \mathrm{~kg} / \mathrm{m}^{3}$ \\
\hline Density of liquid & $\rho_{\mathrm{l}}=8811 \mathrm{~kg} / \mathrm{m}^{3}$ \\
\hline Viscosity & $\begin{array}{l}\mu=0.988 \times 10^{-2} \exp (4620 /(\mathrm{T}+273)) \\
\mathrm{gm} / \mathrm{cm} \mathrm{sec}\end{array}$ \\
\hline $\begin{array}{l}\text { Volumetric heat } \\
\text { generation }\end{array}$ & $\mathrm{Q}_{\mathrm{vol}}=2.15 \mathrm{cal} / \mathrm{cm}^{3} \mathrm{sec}$ \\
\hline
\end{tabular}

Under these conditions, Crepeau and Siahpush [15] showed,

$$
\rho_{s} \Delta h_{f} \frac{d s}{d t}=\frac{\left(s^{2}-r_{0}^{2}\right) \dot{q}+k_{s}\left(T_{m}-T_{0}\right)}{4 s\left(\ln s-\ln r_{0}\right)}
$$

By scaling these terms, we find,

$$
\rho_{s} \Delta h_{f} \frac{s}{t} \sim \frac{s^{2} \dot{q}}{s\left(\ln s-\ln r_{0}\right)}, \frac{r_{0}^{2} \dot{q}}{s\left(\ln s-\ln r_{0}\right)}, \frac{k_{s}\left(T_{m}-T_{0}\right)}{s\left(\ln s-\ln r_{0}\right)}
$$

Rearranging terms and introducing the Stefan number,

$$
\frac{s^{2}}{t} \sim \frac{s^{2} \dot{q}}{\ln \left(s / r_{0}\right) \rho_{s} \Delta h_{f}}, \frac{r_{0}^{2} \dot{q}}{\ln \left(s / r_{0}\right) \rho_{s} \Delta h_{f}}, \frac{\alpha_{s} S t_{s}}{\ln \left(s / r_{0}\right)}
$$

For small Stefan numbers and $\ln \left(s / r_{0}\right) \sim 1$, so that the first and third terms of the right side of Eq. (28) are small, leaving,

$$
\frac{s^{2}}{t} \sim \frac{r_{0}^{2} \dot{q}}{\rho_{s} \Delta h_{f}}
$$

Or rearranging gives,

$$
s \sim \sqrt{\frac{r_{0}^{2} \dot{q}}{\rho_{s} \Delta h_{f}} t}
$$

Now we define the nondimensional time as,

$$
\theta=\frac{\dot{q}}{\rho_{s} \Delta h_{f}} t
$$

So that the scaling relation for the phase change front becomes,

$$
s \sim r_{0} \theta^{1 / 2}
$$

which is a common scaling condition as shown previously [17] 
Equation (26) is compared with Eq. (30) and the result is presented in Figure 3. In this evaluation, it is assumed that $r_{0}=0.05 \mathrm{~m}$, and freezing of $\mathrm{UO}_{2}$ is considered. Both analyses present the same results and at approximately 900 seconds, the melt front reaches the steady-state position.

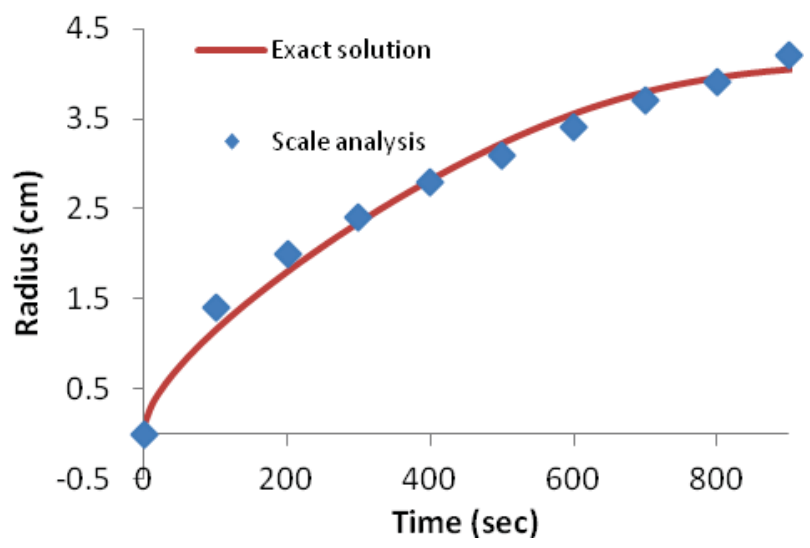

Figure 3. Comparison of closed form solution with results of the scale analysis for freezing with a constant temperature boundary condition.

\section{CONCLUSIONS}

A scale analysis was performed for heat transfer in a cylindrical geometry where the material generates internal heat, under both constant temperature and constant heat flux boundary conditions. The scaling results are similar to analytical results published previously. The distance to the phase front scales with the square root of the heat flux when it dominates, and with the surface heat flux when it is greater than the internal heat generation.

\section{REFERENCES}

[1] Viskanta, R. (1985) "Natural Convection in Melting and Solidification," in Natural Convection, Fundamentals and Applications, eds. S. Kakac, W. Aung, and R. Viskanta, Hemisphere, Washington, DC., pp. 845-877.

[2] Martin, B.W., (1967) "Free convection in a vertical cylinder with internal heat generation," Proc. Royal Society B, 301, pp. 327-341.

[3] Vajrevelu, R., (1979) "Natural Convection at a heated semiinfinite vertical plate with internal heat generation," Acta Mechanica, 34, pp. 153-159.

[4] Daniels, P.G., and O.K. Jones, (1998) "Convection in a shallow rectangular cavity due to internal heat generation," International Journal of Heat and Mass Transfer, 41, pp. 39793987.

[5] Tasaka, Y., Y. Kudoh, Y. Takeda, T. Yanagisawa, (2005), "Experimental investigation of natural convection induced by internal heat generation," Journal of Physics:Conference Series, 14, pp. 168-179.
[6] Joshi, M.V., U.N. Gaitonde, S.K. Mitra, (2006) "Analytical Study of Natural Convection in a Cavity with volumetric heat generation," J. Heat Transfer, 128, pp. 176-182.

[7] Tien, C. and Y.-C. Yen, (1966) "Approximate solution of a melting problem with natural convection," AICHE J. 62, pp. 166-172.

[8] Bejan, A., (2004) Convection Heat Transfer, Wiley, New York, $3^{\text {rd }}$ ed.

[9] Astarita, G. (1997) "Dimensional Analysis, scaling, and orders of magnitude," Chemical Engineering Science, 52, pp. 4681-4698.

[10] Zhang, A. and A. Bejan, (1989) "The problem of timedependent natural convection melting with conduction in the solid," Int. J. Heat Mass Trans. (32) pp. 2447-2457.

[11] Kim, S., and M.C. Kim, (2002) "A scale analysis of turbulent heat transfer driven by buoyancy in a porous layer with homogeneous heat sources," Int. Comm. Heat Mass Trans. 29, pp. 127-134.

[12] Crepeau, J. A. Siahpush and B. Spotten (2009) "On the Stefan Problem with Volumetric Energy Generation," Heat Mass Transfer, 46, pp. 119-128.

[13] Incropera, F.P., and D.P. DeWitt, (2001), Fundamentals of Heat Transfer, $4^{\text {th }}$ ed. Wiley, New York.

[14] Poulikakos, D., Conduction Heat Transfer, Prentice Hall, Englewood Cliffs.

[15] Crepeau, J.C., and A. Siahpush, (2008), "Approximate Solutions to the Stefan Problem with Internal Heat Generation," Heat and Mass Transfer, 44, pp. 787-794.

[16] El-Genk, M., and A.W. Cronenberg, (1978) "An Assessment of Fuel Freezing and Drainage Phenomena in a Reactor Shield Plug Following a Core Disruptive Accident," Nuclear Eng. Design, 47, pp. 195-225.

[17] Siahpush, A. and Crepeau J.C., (2011), "Scale Analysis of Convective Melting with Internal Heat Generation," Proceedings of the ASME/JSME $8^{\text {th }}$ Thermal Engineering Joint Conference, March 13-17, 2011, Honolulu, Hawaii, Paper \#44162. 